\title{
Porencephalic Cyst
}

National Cancer Institute

\section{Source}

National Cancer Institute. Porencephalic Cyst. NCI Thesaurus. Code C99020.

A cong enital or acquired cystic cavity within the cerebral hemisphere. 